\section{FRI0182 EROSIONS AT THE SACROILIAC JOINTS AND FATTY LESIONS AT THE SPINE ARE THE MOST DISCRIMINANT LESIONS FOR RECENT ONSET AXSPA RECOGNITION}

A. Moltó ${ }^{1}$, L. Gossec ${ }^{2}$, M. Lefevre-Colau ${ }^{1}$, R. Beaufort ${ }^{1}$, V. Foltz ${ }^{2}$, J. Laredo ${ }^{3}$, P. Richette ${ }^{3}$, P. Dieudé ${ }^{4}$, P. Goupille ${ }^{5}$, A. Feydy ${ }^{1}$, M. Dougados ${ }^{1} .{ }^{1}$ Cochin; ${ }^{2}$ Pitié Salpetrière; ${ }^{3}$ Lariboisière; ${ }^{4}$ Bichat, Paris; ${ }^{5} \mathrm{CHU}$ Tours, Tours, France

Objectives: To evaluate the performances of MRI (SIJ and Spine) structural lesions suggestive of axSpA for its recognition.

Methods: Observational cross-sectional national multicentre study. Patients: a) Recent onset axSpA patients: first, a sample of 100 patients representative in terms of imaging abnormalities of the global DESIR recent onset axSpA cohort based on the results of the previously published central reading of baseline films of DESIR were selected. b) Recent onset CBP patients: consecutive in- and outpatients consulting for recent mechanical CBP, initiating before the age of $45 \mathrm{y}$ and with a maximum age of $50 \mathrm{y}$, in four tertiary care Hospitals were included in the study. Imaging: MRI scans (T2-STIR and T1 sequences) of the SIJ and cervico-thoracic and thoraco-lumbar spine were performed in both groups with identical protocol. Central reading: an experienced reader (AM) centrally read all MRI scans, blinded for clinical diagnosis. Statistical analysis: prevalence of lesions suggestive of axSpA was compared in both groups. Sensitivity, specificity and positive likelihood ratio $(\mathrm{LR}+)$ of each lesion were calculated.

Results: A total of 98 patients with recent onset CBP were included, and compared to 100 recent onset axSpA patients. Age and gender were comparable (mean (SD) 36.2 (9.9) vs. 32.2 (8.7)y, and $41.8 \%$ and $45 \%$ males, in the CBP vs. axSpA groups, respectively)

Prevalence of chronic lesions of the SIJ was significantly greater in the axSpA group. Presence of at least 3 subchondral bone erosions at the SIJ performed the best for axSpA discrimination. Prevalence of chronic lesions of the spine was comparable in the two groups. The presence of at least 5 fatty lesions was the most discriminant, with high specificity.

Conclusions: Presence of at least 3 erosions at the MRI-SIJ and at least 5 fatty lesions at the MRI-spine seemed to performed well for axSpA recognition.

Disclosure of Interest: None declared

DOI: 10.1136/annrheumdis-2018-eular.4162

\section{FRI0183 CLINICAL PERIPHERAL ENTHESITIS IN THE DESIR PROSPECTIVE LONGITUDINAL AXIAL SPONDYLOARTHRITIS COHORT}

V. Nadon ${ }^{1}$, A. Moltó ${ }^{2}$, A. Etcheto ${ }^{2}$, L. Bessette ${ }^{3}$, L. Michou ${ }^{3}$, M.-A. D'Agostino ${ }^{4}$, P. Claudepierre ${ }^{5}$, D. Wendling ${ }^{6}$, M. Dougados ${ }^{2}{ }^{1}$ Institut Rhumatologie Montreal, Montreal, Canada; ${ }^{2}$ Cochin, Paris, France $;{ }^{3} \mathrm{CHUL}$, Quebec, Canada; ${ }^{4}$ AmbroiseParé, Boulogne-Billancourt, ${ }^{5} \mathrm{Henri}$ Mondor, Créteil; ${ }^{6} \mathrm{CHU}$ Besançon, Besançon, France

Objectives: 1) To describe the prevalence and characteristics of peripheral enthesitis in recent onset axial spondyloarthritis; 2) to estimate the incidence of peripheral enthesitis over time; 3 ) to determine the factors associated with the presence of peripheral enthesitis.

Methods : Patients: 708 patients with recent onset axial spondyloarthritis enrolled in the DESIR cohort (prospective multi-centre, longitudinal). Data collected: patients and spondyloarthritis characteristics at baseline with a specific focus on enthesitis and occurrence of peripheral enthesitis, during the five of years follow-up

Results: At inclusion, 395 patients $(55.8 \%)$ reported peripheral enthesitis. The locations were mainly the plantar fascia $(53.7 \%)$ and the Achilles tendon $(38.5 \%)$. During the 5 year follow-up period, 109 additional patients developed peripheral enthesitis resulting in an estimated (Kaplan Meier technic) percentage of $71 \%$ (95\% Cl: 68-75). Variables associated with peripheral enthesitis in the univariate analysis were: older age, male gender, absence of HLA B27, MRI sacroilitis and fulfilled Modified NY criteria, presence of anterior chest wall pain, peripheral arthritis, dactylitis, psoriasis, high BASDAI, BASFI, mean score ASAS-and the use of NSAID. Only the history of anterior chest wall pain and of peripheral arthritis were retained in the multivariate analysis (Odds Ratio $(\mathrm{OR})=1.6[95 \%$ Confidence interval (1.6 [1.1-2.3], and $\mathrm{OR}=2.1$ [1.4-3.0], respectively).

Conclusions: This study highlights the high prevalence of peripheral enthesitis in recent onset axial spondyloarthritis, and suggests that in combination with peripheral arthritis, enthesitis might have an impact on the burden of the disease.

Acknowledgements: The DESIR cohort is financially supported via an unrestricted grant from PFIZER Ltd. France. Valérie NADON has received a research grant from JANSSEN Ltd Canada.

Disclosure of Interest: None declared

DOI: 10.1136/annrheumdis-2018-eular.4510

\section{FRI0184 \\ HIGH PREVALENCE OF HIDRADENITIS SUPPURATIVA, ESPECIALLY IN FEMALE AXIAL SPONDYLOARTHRITIS PATIENTS WITH HIGH DISEASE ACTIVITY AND POOR QUALITY OF LIFE}

A. Rondags ${ }^{1}$, S. Arends ${ }^{2,3}$, F. Wink ${ }^{3}$, B. Horvath ${ }^{1}$, A. Spoorenberg ${ }^{2,3}$

${ }^{1}$ Dermatology; ${ }^{2}$ Rheumatology and Clinical Immunology, University of Groningen, University Medical Center Groningen, Groningen; ${ }^{3}$ Rheumatology, Medical Center Leeuwarden, Leeuwarden, Netherlands

Background: Hidradenitis suppurativa (HS) is a chronic debilitating inflammatory skin disease. Although HS and axial spondyloarthritis $(\mathrm{SpA})$ share common denominators in the pathogenesis and treatment, little is known about HS associated patient characteristics in axial SpA.

Objectives: To identify patient characteristics associated with HS in a large cohort of axial SpA patients.

Methods: In this cross-sectional study, a self-screening questionnaire based on validated diagnostic HS questions was sent to all axial SpA patients from the Groningen Leeuwarden Axial Spondyloarthritis (GLAS) cohort. Verification of HS diagnosis was done by reviewing medical records for dermatologists diagnosis of $\mathrm{HS}$ and by telephone using another validated diagnostic HS question. These HS questions showed previously high sensitivity and specificity $\left(92 \%-97 \%{ }^{1}\right.$ and $97 \%^{2}$, resp.). Comparative analysis for axial SpA patients with versus without HS was performed. Multivariable logistic regression analysis of patient characteristics was performed to investigate independent predictors for HS in axial SpA.

Results: In total, $75.6 \%$ (449/592) questionnaires were eligible for analyses. Included patients had a mean age of $50 \pm 13$ years, $63 \%$ were male, mean symptom duration was $23 \pm 13$ years, and $78 \%$ were HLA-B27 positive. HS diagnosis could be confirmed in 41 of the 449 respondents, resulting in an estimated prevalence of $9.1 \%$. Assuming that all non-responders never had HS, the minimal HS prevalence rate would be $6.9 \%(41 / 592)$.

In comparison to patients without a positive history of $\mathrm{HS}$, these patients were more frequently female ( $54 \%$ vs. $35 \%, p=0.02)$, showed higher axial SpA disease

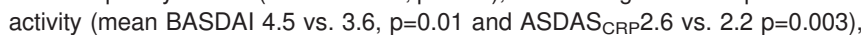
and worse quality of life (QoL) (median ASQoL 9.0 vs. 4.0, $p<0.001$ ). Also, a history of heel enthesitis and dactylitis was more prevalent (34\% vs. $19 \%$, $p=0.03 \%$ and $15 \%$ vs. $6 \%, p=0.05$, respectively). Multivariable analysis showed that a higher score on ASDAS was independently associated with HS (OR: 1.639, 95\% Cl 1.176-2.284)

Conclusions: In our cohort of axial SpA patients, HS is more prevalent than in the general population $\left(6.9 \%-9.1 \%\right.$ and $\sim 1 \%$ resp.). ${ }^{3} \mathrm{HS}$ is associated with high ASDAS, especially in female patients experiencing poor QoL. Additionally, heel enthesitis and dactylitis seems also to be more prevalent in axial SpA patients with HS.

\section{REFERENCES:}

[1] Esmann S, et al. Questionnaire-based diagnosis of hidradenitis suppurativa: Specificity, sensitivity and positive predictive value of specific diagnostic questions. Br J Dermatol 2010;163:102-6.

[2] Vinding GR, et al. The prevalence of inverse recurrent suppuration: A population-based study of possible hidradenitis suppurativa. $\mathrm{Br} \mathrm{J}$ Dermatol 2014;170:884-9.

[3] Miller IM, et al. Prevalence, risk factors, and comorbidities of hidradenitis suppurativa. Dermatologic Clinics 2016;34:7-16.

Disclosure of Interest: A. Rondags: None declared, S. Arends Grant/research support from: Pfizer, F. Wink Consultant for: Abbvie, B. Horvath Grant/research support from: Abbvie, Janssen-Cilag, Novartis, Consultant for: Abbvie, JanssenCilag, Novartis, A. Spoorenberg Grant/research support from: Pfizer, Abbvie, Consultant for: Pfizer, Abbvie, MSD, UCB, Novartis

DOI: 10.1136/annrheumdis-2018-eular.6379

\section{FRI0185 PATIENTS WITH AXIAL SPONDYLOARTHRITIS}

A.S. Buche, L. Preston, N. Barkham. Rheumatology, The Royal Wolverhampton NHS Trust, Wolverhampton, UK, Wolverhampton, UK

Background: Work instability is defined as mismatch between the employee's ability to work and the employer's expectations ${ }^{1}$. $50 \%$ of Ankylosing spondylitis patient lose their job due to disease activity and $50 \%$ of those in job face work instability and job retention problem ${ }^{2}$. Work disability is preceded by a period of work instability, which can be measured by the Ankylosing spondylitis work instability scale (ASWIS) ${ }^{1}$. 